\title{
High-grade Glial Tumors Associated with ETV6-NTRK3 Gene Fusion: Imaging Appearance with Pathological Correlate

\section{Background}

High-grade glial tumors in the pediatric population associated with the ETV6-NTRK3 gene fusion are rare but treatable malignancies, with reports of response to first-generation TRK tyrosine kinase inhibitors.

\section{Materials and Methods}

Five pediatric patients ( 3 female and 2 male; age range, 11 days $4 \mathrm{yrs}$ ) presenting with high-grade glial neoplasms associated with the ETV6-NTRK3 gene fusion were evaluated via MRI.

\section{Case 1}

A 3-year-old female presented with a 2 mo history of morning emesis. Gadolinium-enhanced MRI showed (Fig 1):

Extensive abnormal tissue at the margins of the lateral ventricles

Mixed cystic and solid mass extending into the parietal lobe Tumor did not demonstrate enhancement or reduced diffusion

Leptomeningeal CSF dissemination within the internal auditory canals, distal lumbar spine, and dura of the posterior fossa

Pathologic and genetic analysis confirmed ETV6-NTRK3 gene fusion (Fig 3).

Treatment with a TRK tyrosine kinase inhibitor was initiated with marked clinical and radiological response (Fig 2).

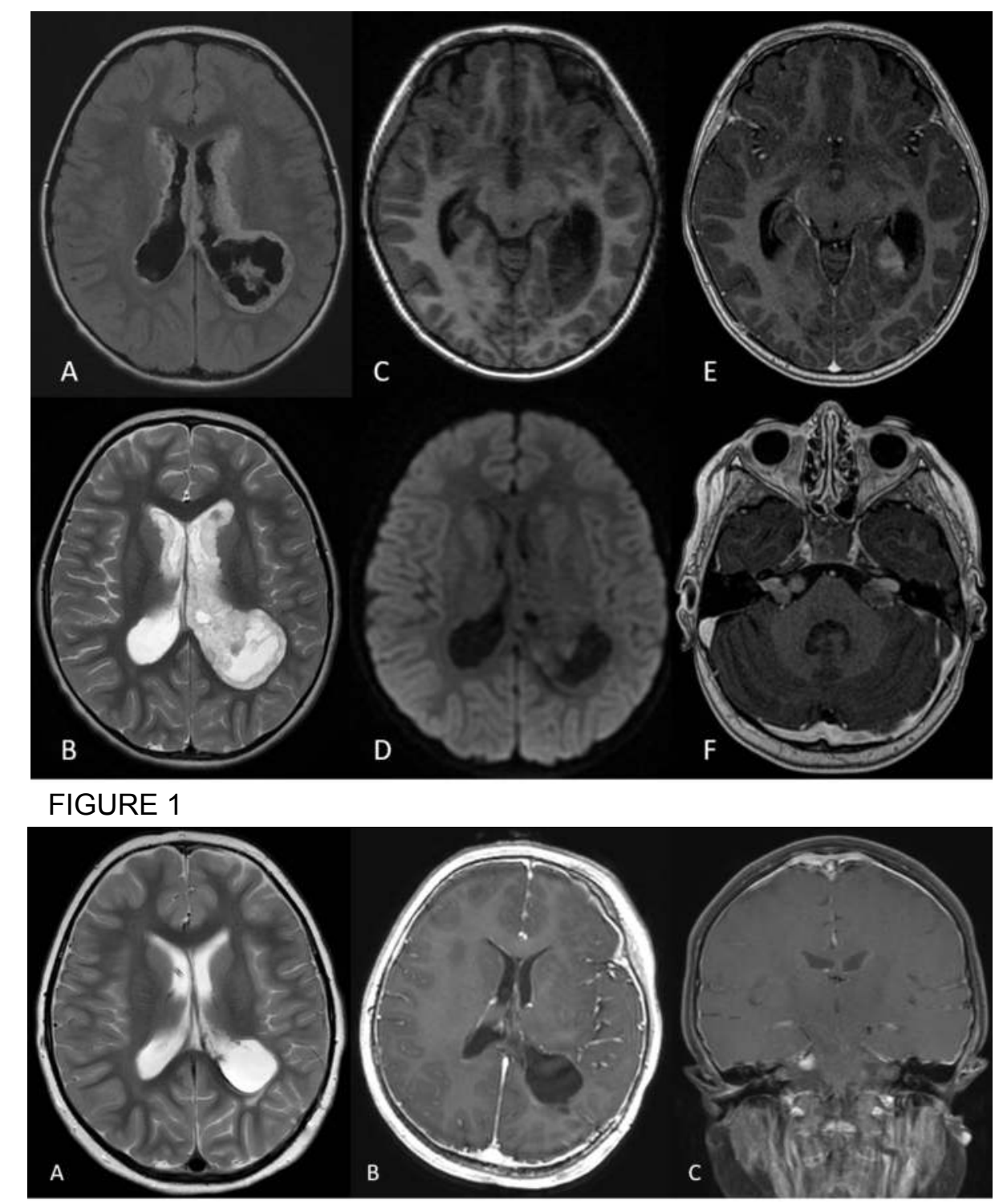

FIGURE 2
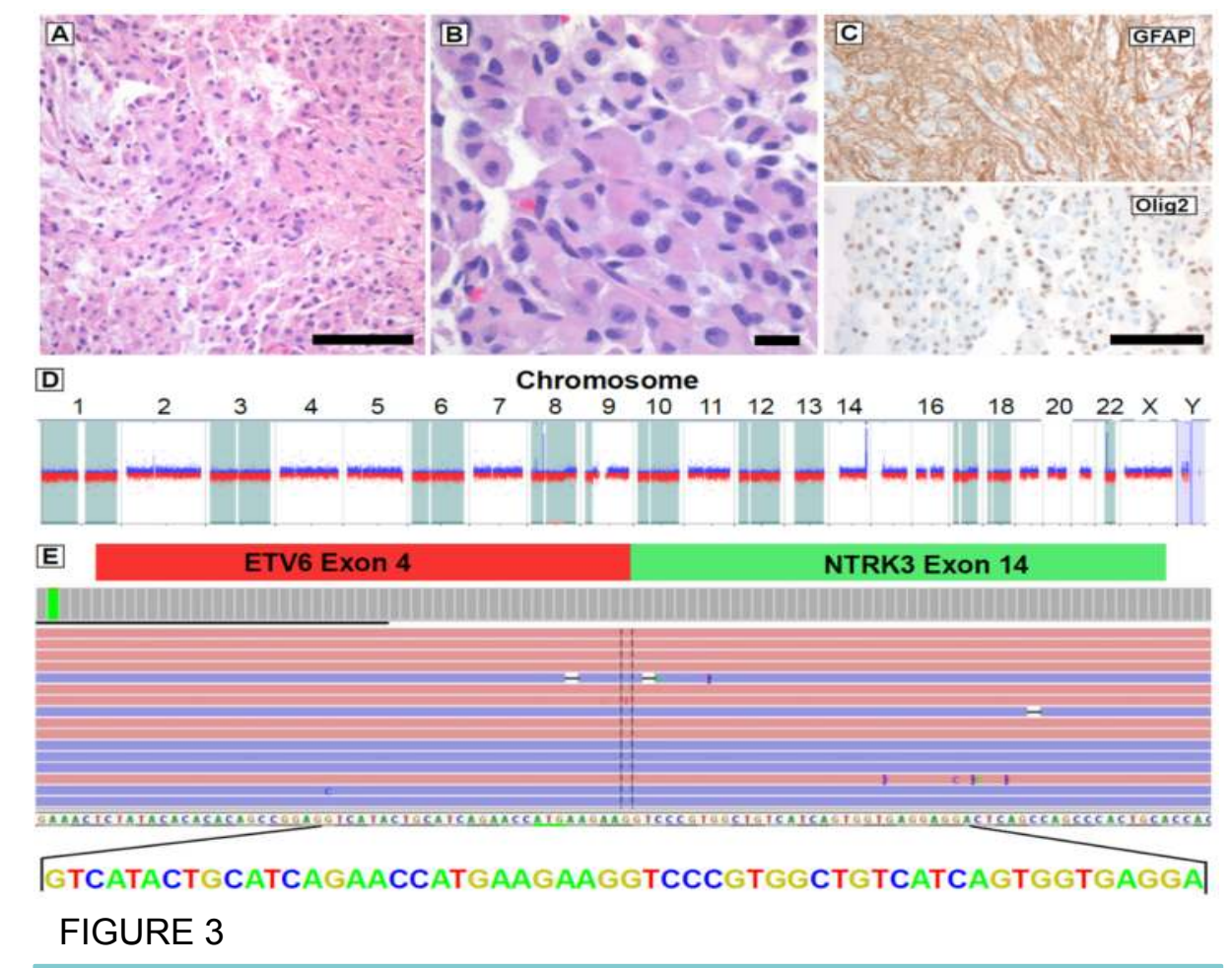

FIGURE 3

$$
\text { Case } 2
$$

A 5-month-old male presented with macrocephaly. MRI revealed (Fig 4):

Large partially cystic mass with a solidly enhancing nodule Hydrocephalus and a large porencephalic cyst

No diffusion restriction

The mass and cyst were resected; disease recurred 3 yrs later and was resected again

Genetic evaluation revealed ETV6-NTRK3 gene fusion

TRK tyrosine kinase inhibitor therapy was initiated with no evidence of disease progression at $2 \mathrm{yr}$ follow up.

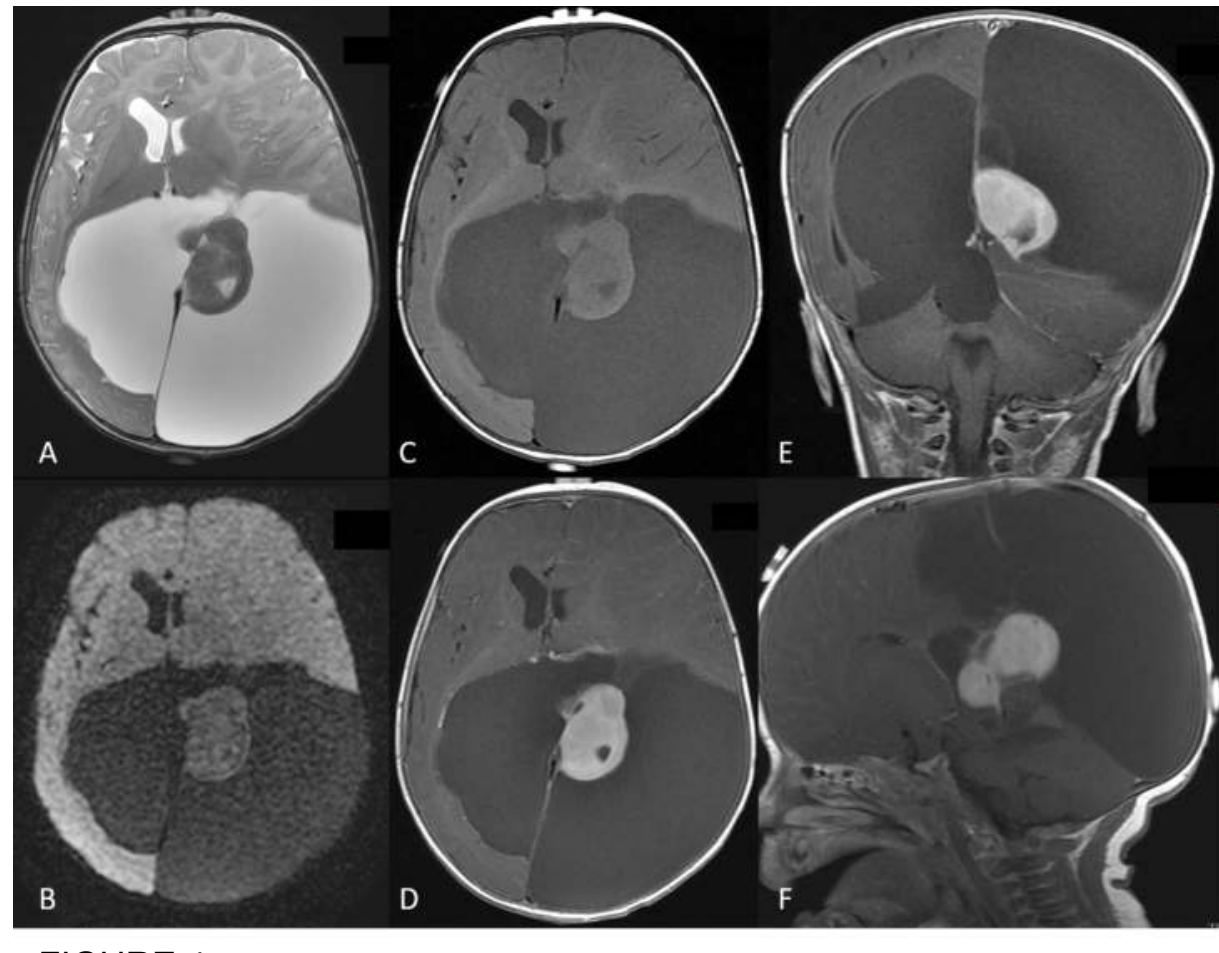

\section{Case 3}

A female twin born at 27 wks gestation was found to have a brain mass on prenatal US and fetal MRI at 26 wks. Post-natal MRI on day 11 of life revealed (Fig 5):

Large heterogeneous mass in left parietal lobe

Large flow voids and areas of diffusion restriction within the mass

Areas of intrinsic T1 shortening and susceptibility artifact

within the mass

Peripheral regions of avid, irregular, nodular contrast

enhancement

Perfusion with arterial spin labeling revealed markedly elevated cerebral blood flow within the mass.

Genetic analysis confirmed ETV6-NTRK3 gene fusion.

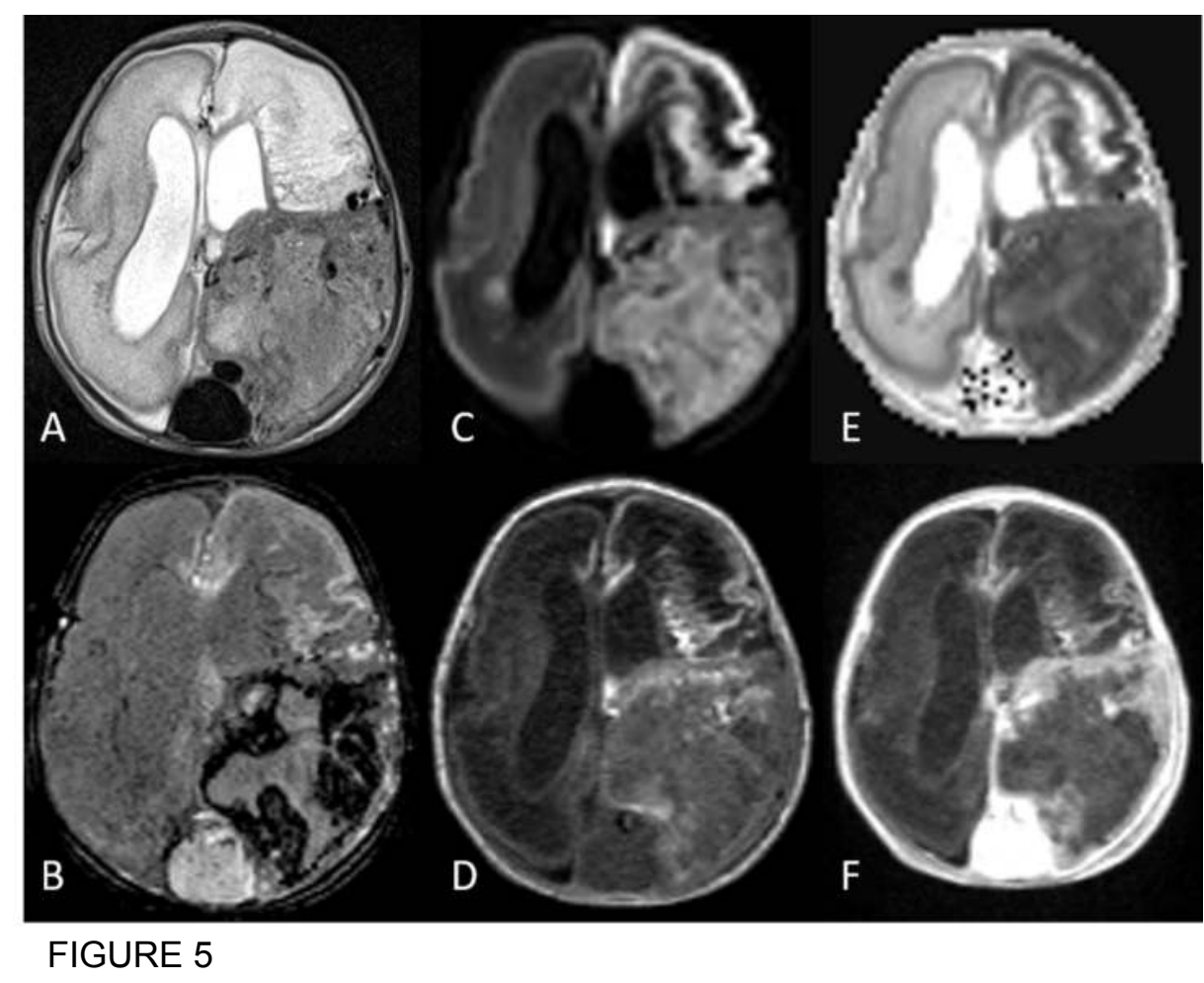

\section{Case 4}

A 4-year-old female presented with morning emesis and headaches.

MRI demonstrated (Fig 6):

Large posterior fossa mass within left cerebellar hemisphere Cystic or necrotic central mass with peripheral rim of irregular, nodular enhancement

Adjacent solidly enhancing tumor mass

Trace susceptibility artifact on SWI imaging

Mass was resected and ETV6-NTRK3 fusion was confirmed on genetic testing.

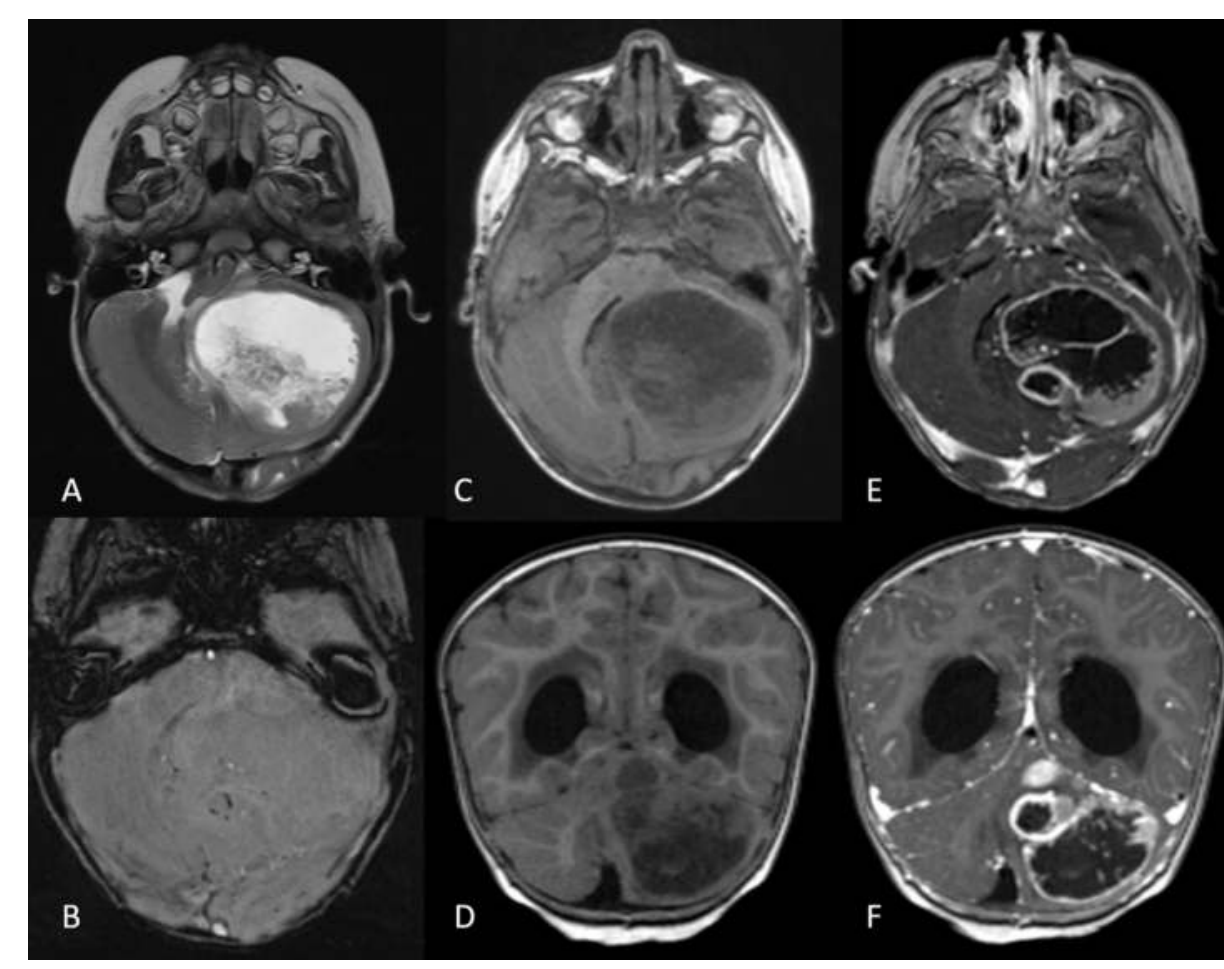

FIGURE 6

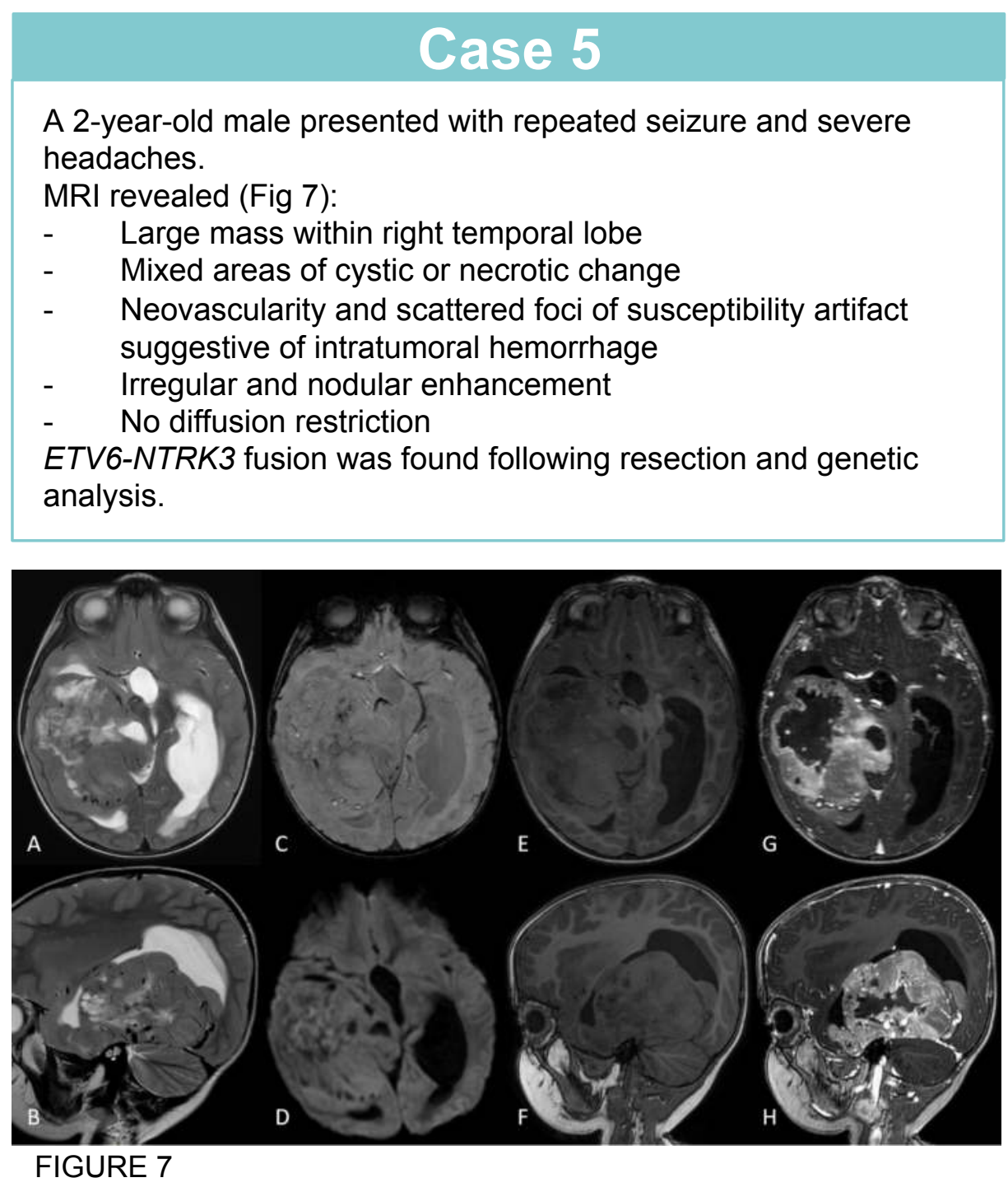

\section{Results}

The cases in this series revealed a heterogeneous imaging appearance of ETV6-NTRK3 fusion gliomas, with findings including mixed cystic and solid masses, irregular and nodular enhancement, neovascularity, and scattered foci of susceptibility artifact.

\section{Conclusions}

These data suggest that despite sharing a common genetic underpinning, imaging findings for ETV6-NTRK3 fusion gliomas are heterogenous. Advances in understanding the evolution and subtypes of these tumors may enable radiologists to further differentiate these neoplasms based on imaging appearance.

\section{Contact}

Joshua P. Nickerson, MD

OHSU Department of Radiology

3181 SW Sam Jackson Park Rd., Portland, OR 97239

\section{References}

Lannon CL, Sorensen PH. ETV6-NTRK3. a chimeric protein tyrosine kinase with 15(3):215-23. Revivity in multiple cell lineages. Semin Cancer Biol. 2005 Jun Knezevich SR, McFadden DE, Tao W, Lim JF, Sorensen PH. A novel ETV6Albert CM, Davis JL, Federman N, Casanova M, Laetsch TW. TRK Fusion Cancers in Children: A Clinical Review and Recommendations for Screening. J Cocco E, Scaltriti M, Drilon A. NTRK fusion-positive cancers and TRK inhibito

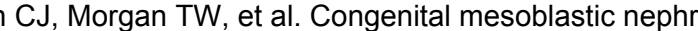
is associated with ETV6-NTRK3 gene fusion: cytogenetic and molecular
relationship to congenital (infantile) fibrosarcoma. Am J Pathol. 1998; 153:148 Tognon C, Knezevich SR, Huntsman D, et al. Expression of the ETV6-NTRK3 Cell. 2002; 2:367-376. Eguchi M, Eguchi-lshimae M, Tojo A, et al. Fusion of ETV6 to neurotrophin-3 3:1355-1363 Forghieri F, Morselli M, Potenza L, et al. Chronic eosinophilic leukaemia with ETV6-NTRK3 fusion transcript in an elderly patient affected with pancreatic

Leeman-Neill RJ, Kelly LM, Liu P, Brenner AV, Little MP, Bogdanova TI, Evdokimova VN, Hatch M, Zurnadzy LY, Nikiforova MN, Yue NJ, Zhang M, rearrangement in radiation-associated thyroid cancer.Cancer. $2014 \mathrm{Mar}$ Nakagawara A: Trk receptor tyrosine kinases: A bridge between cancer and Wu G, Diaz AK, Paugh BS, et al: The genomic landscape of diffuse intrinsic pontine glioma and pediatric non-brainstem high-grade glioma. Nat Genet 2014;46: 444-450. Jones DT, Hutter B, Ja"ger N, et al: Recurrent somatic alterations of FGFR1 and Torre M,Jessop N, Hornick JL, Alexandrescu S. Expanding the spectrum of pediatric NTRK-rearranged fibroblastic tumors to the central nervous system: A case report with RBPMS-NTRK3fusion. Neuropathology. 2018 Dec;38(6): Ziegler DS, Wong M, Mayoh C, Kumar A, Tsoli M, Mould E, Tyrrell V, KhuongQuang DA, Pinese M, Gayevskiy V, Cohn RJ, Lau LMS, Reynolds M, Cox MC, Gitord A, Rodrise M, Gaver driven high-grade glioma Br J Cancer. 2018 Sep:119(6):693-696. doi: 10.1038/ s41416-018-0251-2. Epub 2018 Sep Cocco E, Scaltriti M, Drilon A. NTRK Fusio 41571-018-0113-0. Review. 